\title{
Thyroid storm in a young woman resulting in bilateral basal ganglia infarction
}

\author{
S.R. Page and A.R. Scott
}

Department of Medicine, Derbyshire Royal Infirmary, London Road, Derby DE1 2QY,UK

\begin{abstract}
Summary: We describe a 30 year old woman who presented with thyroid storm. She had non-specific symptoms and few clinical signs of hyperthyroidism despite markedly raised thyroid hormone concentrations. Soon after admission her behaviour became abnormal and her level of consciousness deteriorated. Despite the rapid restoration of thyroid hormone concentrations to normal using conventional therapies, and correction of hypoxia resulting from acute pulmonary oedema, her level of consciousness did not improve. Cranial CT scanning revealed extensive bilateral basal ganglia infarction, a previously unreported complication of thyroid storm. This observation suggests that thyroid storm may predispose to hypoxic neurological damage.
\end{abstract}

\section{Introduction}

Thyroid storm is an increasingly rare complication of untreated or partially treated hyperthyroidism, associated with cardiovascular, hepatic, gastrointestinal and neurological dysfunction. ${ }^{1}$ Mortality is approximately $20 \%{ }^{2}$ and successful treatment depends on early recognition and aggressive treatment. Most patients present with exaggerated signs of hyperthyroidism and extreme agitation, emotional lability and restlessness. Much less commonly, apathy, stupor and a paucity of signs of hyperthyroidism occur and a high index of suspicion is required in order that the diagnosis is not missed.

A number of neurological complications including altered behaviour, ${ }^{3}$ seizures, ${ }^{4}$ pyramidal tract disease $^{5}$ and choreoathetosis ${ }^{6}$ have been described in association with hyperthyroidism. We describe a woman presenting with thyroid storm who developed the previously unreported complication of extensive bilateral basal ganglia infarction.

\section{Case report}

A 30-year-old non-English-speaking Asian female was admitted with a 2-week history of nausea, vomiting, abdominal pain, fever and frontal headache.

On examination she was withdrawn with a temperature of $37.2^{\circ} \mathrm{C}$, a resting pulse of 102 beats/minute and a small diffuse goitre with no

Correspondence: S.R. Page, M.D., M.R.C.P

Accepted: 16 March 1993 bruit. Her hands were cool and dry and she had no signs of thyroid ophthalmopathy. A provisional diagnosis of a nonspecific viral illness was made. The full blood count, urea and electrolytes, chest radiograph and electrocardiogram were normal. Blood cultures were sterile.

Thirty-six hours later her behaviour was causing concern. She had undressed in front of other patients on the ward and had been incontinent of urine. She would not speak to medical or nursing staff (via an interpreter). Examination revealed no focal neurological signs but her temperature had risen to $38.5^{\circ} \mathrm{C}$ and she had a resting pulse of 120 beats/minute. Cranial computed tomographic (CT) scanning was reported as showing several low attenuation areas in the right temporal lobe. An electroencephalogram was consistent with, but not diagnostic of, a generalized encephalopathy. Examination of the cerebrospinal fluid (CSF) showed a protein of $0.52 \mathrm{~g} / 1$ (normal range $0.1-0.4 \mathrm{~g} / \mathrm{l})$.

A diagnosis of herpes simplex encephalitis was made and acyclovir was commenced. However, her condition deteriorated over the next 18 hours, she became unconscious and developed bilateral extensor plantar responses. Her temperature rose to $39.5^{\circ} \mathrm{C}$ and her resting pulse rose to 150 beats/ minute. Her admission thyroid function tests became available and revealed a serum free thyroxine $\left(\mathrm{fT}_{4}\right)>100 \mathrm{nmol} / \mathrm{l}(8-24 \mathrm{nmol} / \mathrm{l})$, serum free triiodothyronine $\left(\mathrm{fT}_{3}\right)>35 \mathrm{pmol} / \mathrm{l}(4-8 \mathrm{pmol} / \mathrm{l})$, serum thyrotrophin $(\mathrm{TSH})<0.04 \mathrm{mU} / 1 \quad 0.3-$ $4.9 \mathrm{mU} / \mathrm{l})$. She had positive thyroid microsomal antibodies with a titre of $1: 6,400$. A diagnosis of 
thyroid storm was made and she was treated with propylthiouracil $600 \mathrm{mg}$ daily and sodium iopodate $500 \mathrm{mg}$ twice daily, via a nasogastric tube, and with intravenous propanolol and dexamethasone. Serum $\mathrm{fT}_{3}$ and $\mathrm{fT}_{4}$ concentrations fell rapidly to normal within 4 and 15 days, respectively. Acyclovir was continued until CSF culture and assay for herpes simplex antigen were reported negative.

She developed clinical signs of pulmonary oedema shortly after commencing propanolol. Arterial oxygen fell to $50.1 \mathrm{mmHg}$ (normal 90-120 $\mathrm{mmHg}$ ) and she required endotracheal intubation and assisted ventilation. Hypoxia was neither severe nor prolonged. She remained in sinus rhythm throughout her illness. A repeat chest radiograph was consistent with pulmonary oedema and she responded rapidly to a single dose of intravenous frusemide $(40 \mathrm{mg})$. Cross-sectional echocardiography showed normal left ventricular size and function with no evidence of intra-cardiac thrombus. Assisted ventilation was continued for 2 weeks due to her neurological state after which she was gradually weaned. She appeared 'locked-in' able to follow with her eyes but otherwise make no purposeful movements. A repeat cranial CT scan demonstrated extensive bilateral basal ganglia infarction but normal temporal lobes (Figure 1). Nine months later she remains quadriplegic and totally dependent on nursing care. Her hyperthyroidism is controlled with propylthiouracil $150 \mathrm{mg}$ daily.

\section{Discussion}

Coma is a recognized, though rarely reported $\frac{\pi}{2}$ feature of thyroid storm. The underlying pathological mechanisms are poorly understood. Animal $\rightleftharpoons$ studies suggest that prevailing thyroid hormone $\stackrel{\overrightarrow{\mathcal{O}}}{\stackrel{\rho}{\sigma}}$ concentrations may influence neurotransmitter $\bar{c}$ concentrations, ${ }^{7} \alpha$ and $\beta$ receptor number and 흘 function, ${ }^{7,8}$ and the activity of certain enzymes,, $10 \frac{\bar{m}}{7}$ though the relationship of such changes to $\stackrel{\mathbb{Q}}{\Omega}$ neurophysiological events in man is unknown. An additional, and previously unreported, complication of thyroid storm in the present case was the development of bilateral basal ganglia infarcts. The $\vec{\omega}$ basal ganglia are particularly prone to hypoxic $\stackrel{\circ}{\circ}$ damage and bilateral infarction has been described $\stackrel{\circ}{\circ}$ in association with carbon monoxide poisoning, ${ }^{11} 3$ drowning ${ }^{12}$ and attempted strangulation. ${ }^{13}$ In these 8 cases, however, neurological symptoms evolved $\infty_{0}$ over several weeks after the hypoxic insult. It is $\vec{\sigma}$ possible that the hypoxic episode described in the $\stackrel{\infty}{\omega}$ present case was sufficient to account for the $\omega$ extensive infarction. However, since the hypoxia was neither severe nor prolonged, it seems likely $\vec{O}$ that the extreme thyrotoxic state, perhaps through $\bigcirc$ increased tissue oxygen demand or increased sym- $\stackrel{0}{0}$ pathetic nervous activity may have increased the $\stackrel{\mathbb{C}}{-}$ susceptibility of the basal ganglia to hypox\& $\overrightarrow{0}$ damage. It is noteworthy, in view of the effect thyroid hormones on $\alpha$ and $\beta$ receptor number an function, ${ }^{8}$ that catecholamines released in areas

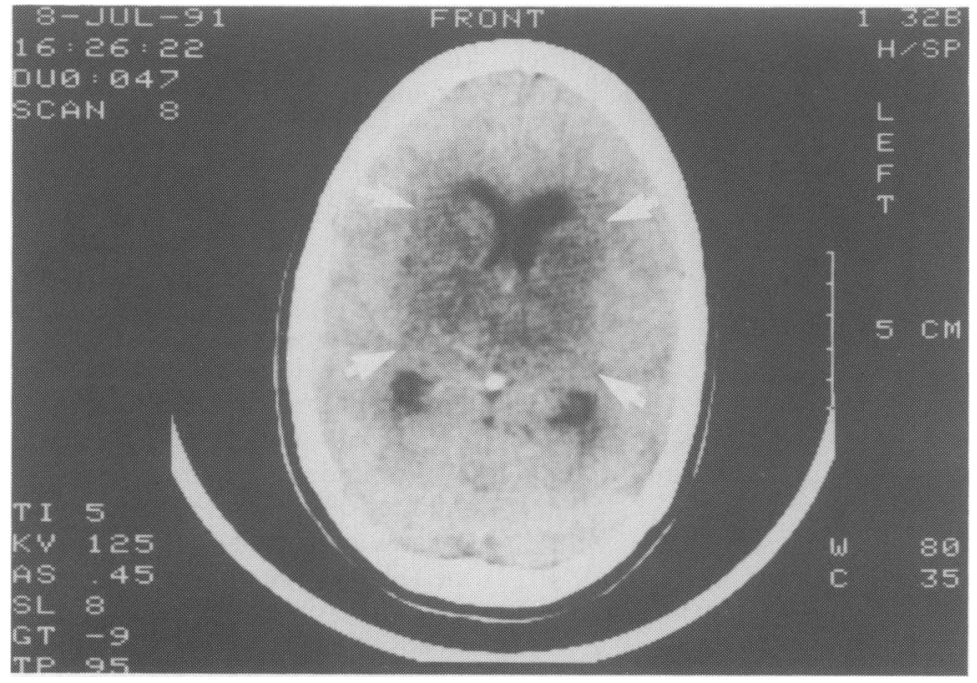

Figure 1 Cranial CT scan showing extensive bilateral basal ganglia infarcts (area within arrows). 
ischaemia may constrict cerebral blood vessels and lead to extension of ischaemic lesions. ${ }^{14}$

Systemic thromboembolic disease in hyperthyroidism is uncommon and usually associated with paroxysmal or sustained atrial fibrillation. ${ }^{15,16}$ In the present case no cardiac arrhythmias were noted and there was no evidence of valvular heart disease, cardiac chamber enlargement or intracardiac thrombus on cross-sectional echocardiography. It is unlikely, therefore, that the basal ganglia infarcts were the result of cardiac emboli.

No histopathological studies of the basal ganglia in thyroid storm have been reported and, in two previously reported cases where thyroid storm was complicated by coma, no abnormalities were demonstrated on cranial CT scanning and complete recovery occurred. ${ }^{17,18}$

Thyroid storm usually presents with an acute exacerbation of the hyperthyroid state and marked hyperactivity, restlessness and agitation. Often a precipitating factor such as surgery, radioactive iodine therapy or intercurrent illness in a previously untreated or partially treated patient with hyperthyroidism can be identified. ${ }^{1,19}$ The lack of classical features of hyperthyroidism, the with- drawn and apathetic behaviour and the absence of an identifiable precipitating factor for thyroid storm are all unusual features of this case. Treatment of thyroid storm is aimed at reducing both the synthesis and secretion of thyroid hormones and inhibiting the peripheral conversion of $T_{4}$ to $T_{3}{ }^{19,20}$ Combination therapy using propylthiouracil and the oral cholecystographic agent sodium iopodate is effective in inhibiting both the synthesis and release of thyroid hormones and the peripheral deiodination of $T_{4}$ to $T_{3}{ }^{21}$ and, in the present case, reduced serum $\mathrm{fT}_{3}$ concentrations to normal within 96 hours.

The mortality of thyroid storm is approximately $20 \%$ and delay in diagnosis is likely to have an adverse effect on outcome. We report the present case to emphasize that thyroid function should be assessed in patients presenting with abnormal or altered behaviour irrespective of the presence or absence of physical signs of hyperthyroidism. The clinical features described in this case suggest that severe hyperthyroidism may predispose to cerebral hypoxic damage and that hypoxia should be avoided in the management of thyroid storm.

\section{References}

1. Waldstein, S.S., Slodki, M.D., Kaganiec, G.I. et al. A clinical study of thyroid storm. Ann Intern Med 1960, 52: 626-642.

2. Mazzaferri, E.L. \& Skillman, T.G. Thyroid storm: a review of 22 episodes with special emphasis on the use of guanethidine. Arch Intern Med 1969, 124: 684-690.

3. Rockey, P.H. \& Grief, R.J. Behavioral function in hyperthyroidism. Improvement with treatment. Arch Intern Med 1980, 140: 1194-1197.

4. Jabbari, B. \& Huott, A.D. Seizures in thyrotoxicosis. Epilepsia 1980, 21: $91-96$

5. Shaw, P.J., Bates, D. \& Kendall-Taylor, P. Hyperthyroidism presenting as pyramidal tract disease. $\mathrm{Br}$ Med $J$ 1988, 297: $1395-1396$.

6. Fishbeck, K.H. \& Layzer, R.B. Paroxysmal choreoathetosis associated with thyrotoxicosis. Ann Neurol 1979, 6: 453-454.

7. Savard, P., Merand, Y., Dipaolo, T. et al. Effect of thyroid state on serotonin, 5-hydroxyindolacetic acid and substance $P$ contents in discrete brain nuclei of adult rats. Neuroscience 1983, 10: 1399-1404.

8. Atterwill, C.K., Bunn, S.J., Atkinson, D.J. et al. Effect of thyroid status on presynaptic alpha-2 adrenoceptor function and beta adrenoceptor binding in the rat brain. $J$ Neural Transmission 1984, 59: 43-55.

9. Fernandez-Pastor, J.M., Morrel, M., Menendez-Patterson, A. et al. Effect of experimental changes in thyroid function on oxidative metabolism and glutamate dehydrogenase activity in the limbic system of the rat. Rev Espanol Fisiol 1983, 39: $311-316$.

10. Murthy, A.S. \& Baquer, N.Z. Changes of pyruvate dehydrogenase in rat brain with thyroid hormones. Enzyme 1982, 28: $48-53$.

11. Choi, H.S. Delayed neurological sequelae in carbon monoxide intoxication. Arch Neurol 1983, 40: 433-435.

12. Murray, R.R., Kapila, A., Blanco, E. et al. Cerebral computed tomography in drowning victims. Am J Neuroradiol 1984, 5: 177-179.

13. Hori, A., Hirose, G., Kataoka, S., Tsukada, K., Furui, K. \& Tonami, H. Delayed post-anoxic encephalopathy after strangulation: serial neuroradiological and neurochemical studies. Arch Neurol 1991, 48: 871-874.

14. Zervas, N.T., Lavyne, M.H. \& Negoro, M. Neurotransmitters and the normal and ischemic cerebral circulation. $N$ Engl J Med 1975, 293: 812-816.

15. Parker, J.L. \& Lawson, D.H. Death from thyrotoxicosis. Lancet 1973, ii: 894-895.

16. Giddings, H.B. \& Surks, M.I. Cerebral embolization in atrial fibrillation complicating hyperthyroidism. J Am Med Assoc 1978, 240: 2567-2568.

17. Newcomer, J., Haire, W. \& Hartman, C.R. Coma and thyrotoxicosis. Ann Neurol 1983, 14: 689-690.

18. Aiello, D.P., DuPlessis, A.J., Pattishall, E.G. \& Kulin, H.E. Thyroid storm presenting with coma and seizures in a 3-year old girl. Clin Pediat 1989, 28: 571-574.

19. McDermott, M.T., Kidd, G.S., Dodson, L.E. et al. Radioiodine-induced thyroid storm. Am J Med 1983, 75: $353-359$.

20. Burger, A.G. \& Philippe, J. Thyroid emergencies. In: Burger, A.G. \& Philippe, J. (eds) Bailliere's Clinical Endocrinology and Metabolism, Vol. 6, no. 1, Endocrine Emergencies. W.B. Saunders, London, 1992, pp. 77-93.

21. Roti, E., Robushi, G., Manfredi, A. et al. Comparative effects of sodium iopodate and iodide on serum thyroid hormone concentrations in patients with Graves' disease. Clinical Endocrinol 1985, 22: 489-496. 